\title{
A Novel Analytical Method for Evaluating the Characteristics of Hydraulic Jump at a Positive Step
}

\author{
Milad Mohammadi ${ }^{1}$, Mohammad Nazari-Sharabian ${ }^{2, *(D)}$ and Moses Karakouzian ${ }^{2}$ (D) \\ 1 Department of Civil Engineering, Isfahan University of Technology, Isfahan 8415683111, Iran; \\ milad.mohammadi@cv.iut.ac.ir \\ 2 Department of Civil and Environmental Engineering and Construction, University of Nevada, \\ Las Vegas, NV 89154, USA; mkar@unlv.nevada.edu \\ * Correspondence: nazarish@unlv.nevada.edu; Tel.: +1-702-205-9336
}

Citation: Mohammadi, M.;

Nazari-Sharabian, M.; Karakouzian, M. A Novel Analytical Method for Evaluating the Characteristics of Hydraulic Jump at a Positive Step. Water 2021, 13, 2005. https:// doi.org/10.3390/w13152005

Academic Editor: Paweł M. Rowiński

Received: 30 May 2021

Accepted: 20 July 2021

Published: 21 July 2021

Publisher's Note: MDPI stays neutral with regard to jurisdictional claims in published maps and institutional affiliations.

Copyright: (c) 2021 by the authors. Licensee MDPI, Basel, Switzerland. This article is an open access article distributed under the terms and conditions of the Creative Commons Attribution (CC BY) license (https:// creativecommons.org/licenses/by/ $4.0 /)$.

\begin{abstract}
We present a new method to evaluate the hydraulic jump characteristics in a horizontal rectangular channel with a positive step. We considered the flow curvature effect and the free surface's small rise at the A-type hydraulic jump's end. First, we present a novel method to give jump length estimation based on the similarity of the jump and the turbulent wall-jet, considering the pressure gradient. Then, considering the jump as a curvilinear flow and using a one-dimensional momentum equation, we present an accurate expression for the conjugate flow depth regarding the initial Froude number and step height. Finally, we compute the jump's energy dissipation rate. Compared to the theoretical models for conjugate flow depth in a hydraulic jump, the proposed equation in this study fit the experimental data better, even for high steps and large initial Froude numbers. However, for low Froude numbers $\left(F_{1}<5\right)$, the equation was less accurate in estimating the jump length. Regarding the jump's energy dissipation rate, the results agreed well with the experimental data from previous investigations. However, it is noted that the increased energy dissipation rate dwindled in larger Froude numbers.
\end{abstract}

Keywords: hydraulic jump; positive step; jump length; conjugate flow depth; flow curvature; wall jet

\section{Introduction}

Hydraulic jump has been widely used as an energy dissipater in stilling basin design. A more efficient stilling basin can be designed if the sequent depth is lower, jump length is shorter, and energy loss in the jump is higher than that in the classical jump [1]. Using structures such as sills, steps, etc., these objectives can be achieved. In addition, steps are used to control the hydraulic jump's position. According to Hager and Bretz [2], in a hydraulic jump, if the whole jump length occurs upstream of a positive step and ends at the step brink, it is classified as an A-type hydraulic jump (Figure 1). While numerous investigations have been conducted on jumps at negative steps, few have been conducted on jumps at positive steps. However, Einwachter [3] simplified the momentum equation to a non-dimensional form as:

$$
F_{1}^{2}=\frac{Y\left\{(Y+S)^{2}-1\right\}}{2(Y-1)}
$$

in which:

$$
F_{1}^{2}=\frac{q^{2}}{g h_{1}^{3}} ; Y=\frac{h_{3}}{h_{1}} ; S=\frac{s}{h_{1}}
$$

where $F_{1}$ is the initial Froude number; $q$ is the unit discharge; $g$ is the gravitational acceleration; $h_{1}$ is the flow depth just before the jump; $Y$ is the conjugate flow depth; $h_{3}$ is the tail water depth; $S$ is the relative step height; and $s$ is the step height (Figure 1). 


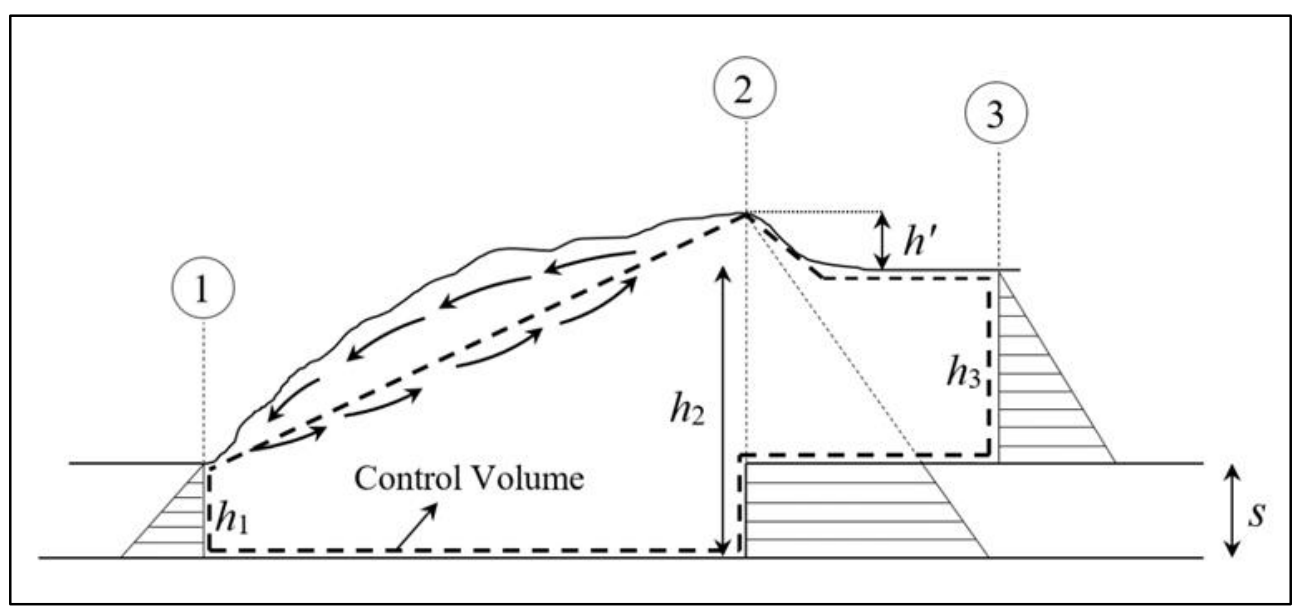

Figure 1. Sketch of an A-type hydraulic jump at a positive step.

Later, Forster and Skrinde [4] modified Einwachter's analytical model as:

$$
F_{1}^{2}=\frac{3 Y(Y+S)^{2}}{8(Y+S)}
$$

Hager and Sinniger [5] extended the theoretical model and extracted expressions for flow characteristics as:

$$
\begin{gathered}
F_{1}^{2}=\frac{Y\left\{(Y+S)^{2}+S^{2}-1\right\}}{2(Y-1)} \\
\frac{\Delta E}{E_{1}}=\left(1-\frac{\sqrt{2}}{F_{1}}\right), F_{1}>1.5 \\
L_{j}=6\left(h_{3}+\frac{6 s}{5}\right)
\end{gathered}
$$

where $\Delta E$ is the energy dissipation between sections 1 and $3 ; E_{1}=h_{1}+q^{2} /\left(2 g h_{1}^{2}\right)$; and $L_{j}$ is the jump length.

Hager and Bretz [2] conducted an experimental study and identified four flow regimes at a positive step. They also confirmed previous analytical models. Furthermore, Quraishi and Al-Brahim [6] studied jumps at positive steps in sloping channels. They presented a modified Froude number by which to estimate the conjugate flow depth. In another study, Husain et al. [7] extracted empirical equations to estimate the conjugate flow depth and jump length for any jump type at a positive step. Later, Negm [8] presented a different modified Froude number form for jumps at positive steps, in which channel slope and step height effects are inserted separately. Although most suggested solutions for the flow characteristics of a hydraulic jump with a positive step have good accuracy levels, there is still a great complexity: none have an uncomplicated structure or a closed-form representation to deal with the non-hydrostatic pressure distribution.

Therefore, we modified the method presented by Hager and Sinniger [5] to present a more accurate closed-form approximation for the conjugate flow depth. The heart of the present approximation relies on a quantity that can represent the non-hydrostatic pressure at the step section, along with the small rise of the jump free surface at the step brink.

\section{Proposed Model}

\subsection{Jump Length}

The first challenge is to estimate the A-type hydraulic jump's length at a positive step. A hydraulic jump downstream of a sluice gate can be modeled as a turbulent wall-jet. The proposed method aims to consider the pressure gradient as an effective parameter to reach 
a new decay equation form. We also applied appropriate velocity distribution and growth rate for the wall jet. For this purpose, similar to Rajaratnam's dimensional analysis [9], we could assume:

$$
u_{m}=f\left(M_{1}, \rho, x, \frac{d p}{d x}\right)
$$

where $M$ is the momentum flux and $d p / d x$ is the pressure gradient. Applying dimensional analysis and using Rajaratnam's [10] experimental data, we obtain the maximum velocity decay equation as:

$$
\frac{u_{m}}{v_{1}}=-0.91\left(\sqrt{\frac{x}{h_{1}}} \frac{g}{2 v_{1}^{2}} \frac{h_{3}^{2}-h_{1}^{2}}{L_{j}}\right)+\frac{2.55}{\sqrt{x / h_{1}}}
$$

where $u_{m}$ is the maximum velocity of the jet at any section $(x)$ and $L_{j}$ is the jump length. The first term on the right-hand-side of Equation (8) indicates the pressure gradient effect. Figure 2 compares Equation (8) with previous classical hydraulic jump experiments for different initial Froude numbers. The curve has a sharp fall followed by a milder fall; the closer to the jump's beginning, the faster the velocity decay. Equation (8)'s prediction does not differ for various initial Froude numbers, nor the data.

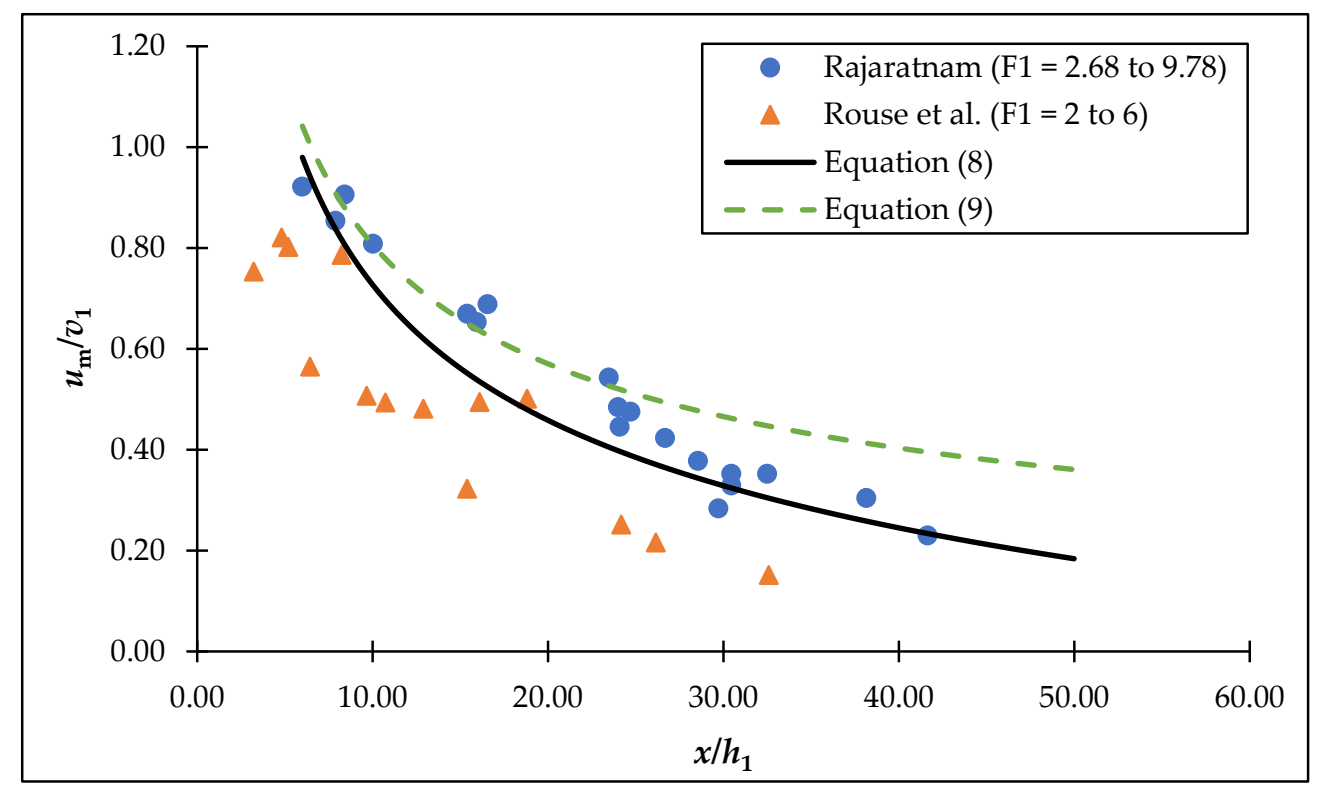

Figure 2. Maximum velocity decay for the hydraulic jump.

More result divergence is detected with Rouse et al.'s [11] data. Holistically, Equation (8) seems to be adequately accurate to estimate the jump's maximum velocity decay. For the no pressure gradient case (the classical wall-jet), Equation (8) reads as:

$$
\frac{u_{m}}{v_{1}}=\frac{2.55}{\sqrt{x / h_{1}}}
$$

As expected, Equation (9) lies above Equation (8), indicating a slower decay rate for the classical wall-jet. Now, an appropriate velocity distribution for the jump is required. Among numerous expressions for the jump's velocity distribution, Ohtso et al. [12] assumed the initial flow condition as a partially developed flow and presented the hydraulic jump's velocity distribution as:

$$
\frac{u}{u_{m}}=\operatorname{Exp}\left\{-\frac{1}{2}\left[1.765\left(\frac{y-\delta}{b}\right)\right]^{2}\right\}
$$


where $b$ is the flow depth from the bottom, where the flow velocity is $u_{m} / 2$, and $\delta$ is the maximum velocity depth. In order to apply Equation (10), expressions for $b$ and $\delta$ should be determined. Various expressions have been suggested, but only a few consider partially developed inflow conditions. The two most accurate are the relations given by Chanson and Brattberg [13], as $\delta / b=0.25$ and $b=0.11 x+1.39 h_{1}$. Combining Equations (8) and (10) results in:

$$
\frac{v_{1}}{v_{3}} \operatorname{Exp}\left[-\frac{1}{2}\left(1.765\left[\frac{y-\delta}{b}\right]\right)^{2}\right]\left(-0.91\left(\sqrt{\frac{x}{h_{1}}} \frac{g}{2 v_{1}^{2}} \frac{h_{3}^{2}-h_{1}^{2}}{L_{j}}\right)+\frac{2.55}{\sqrt{x / h_{1}}}\right)=1
$$

Replacing $y=h_{3}$, at which $x=L_{j}$, and after few manipulations, the final equation for the jump length in a dimensionless form is presented as:

$\operatorname{Exp}\left(-1.56\left[\frac{\left(h_{3} / h_{1}\right)\left[1-0.03\left(L_{j} / h_{3}\right)\right]-0.85}{1.39+0.11\left(h_{3} / h_{1}\right)\left(L_{j} / h_{3}\right)}\right]^{2}\right)\left(\frac{h_{3}}{h_{1}} / \frac{L_{j}}{h_{3}}\right)^{1 / 2}\left[\frac{-0.46}{F_{1}^{2}}\left(\left(\frac{h_{3}}{h_{1}}\right)^{2}-1\right)+2.55\right]=1$

where $h_{3} / h_{1}$ can be defined by the Belanger equation.

A comparison of Equation (12)'s predictions with the experimental results from Woycicki [14], Einwachter [3], Hager and Sinniger [5], and Chow [15] is shown in Figure 3. Compared to the curves of Hager and Sinniger [5], and Chow [15], Equation (12) indicates a more rational trend, in which the jump length estimation is closer to the data at lower initial Froude numbers. In fact, Equation (12) shows a similar trend to the experimental data, which is more discernable for higher steps. However, for low Froude numbers $\left(F_{1}<5\right)$, Equation (12) was unable to estimate the jump length, as were the previous estimations. Moreover, larger step heights resulted in more data convergence, whereas little deviation was seen for different step heights at large Froude numbers. The small overestimation of Equation (12) could be justified as the consequence of the wall jet's velocity distribution assumption. The step's presence stagnates the approaching velocity, and thus changes the velocity distribution. Furthermore, since few experimental studies have been conducted on jump length at a positive step, more research is necessary to more accurately examine the subject.

\subsection{Conjugate Flow Depth}

The necessary parameters for the A-type hydraulic jump at a positive step are shown in Figure 1 , where $h_{2}$ is the flow depth just before the step. A small flow rise, $h^{\prime}$, is noticeable just at the step. To predict the hydraulic jump's conjugate flow depth with a positive step, we applied a momentum equation in the horizontal direction. We assumed the momentum correction factor to be unity, and neglected the frictional force. We also assumed a linear variation in bed pressure over the roller length. The velocity distribution was uniform, and we considered the flow one-dimensional in the longitudinal direction. Using the control volume shown in Figure 1, the 1-D momentum equation for the unit discharge $(q)$ results in:

$$
F_{p_{1}}-F_{p_{3}}-F_{p_{s}}-F_{c}=\rho q\left(v_{3}-v_{1}\right)
$$

where $F_{p}$ is the pressure force; $v$ is the average velocity; $F_{c}$ indicates the flow curvature effect; $\rho$ is the mass density; and indices 1, 2, 3 and $s$ refer to sections (1), (2), (3), and at the step, respectively. 


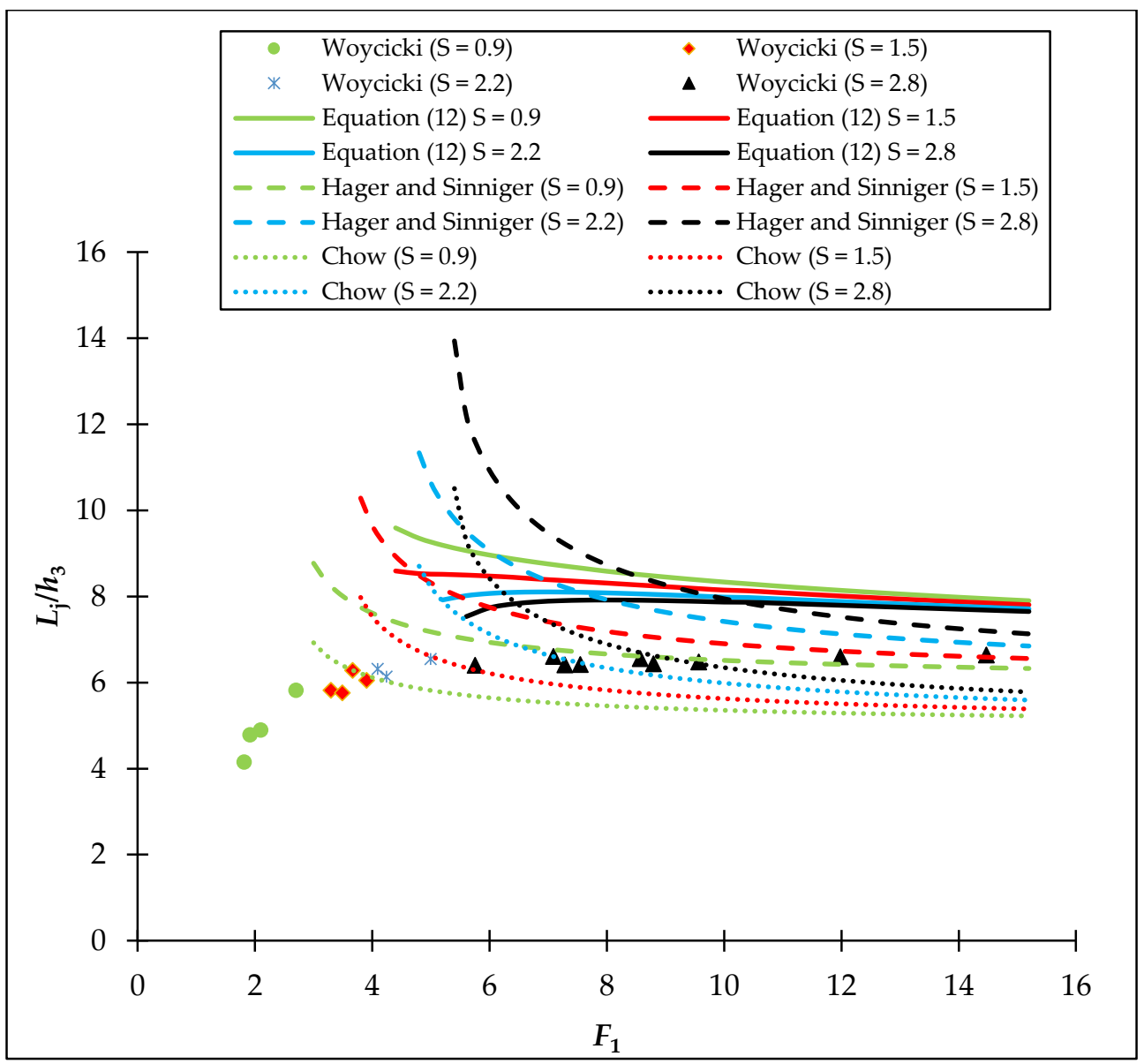

Figure 3. Relative jump length variation with initial Froude number.

The small jump profile rise at section (2), $h^{\prime}$, is justified by the stagnation effect at the end of the hydraulic jump roller, where the whole kinetic energy transforms into the potential energy.

Another justification for the rise is based on the free surface profile. In a horizontal channel, normal flow depth is infinite, and the free surface profile tends to reach the normal depth downstream. As a result, the flow loses its specific energy at section (2), which is expressed as $E=h_{2}+\frac{v_{2}^{2}}{2 g}$. Combined, these set up the primary motivations to look for a closed-form solution for $h^{\prime}$ as:

$$
h \prime=\frac{v_{2}^{2}}{2 g}
$$

The next challenge is to determine the $F_{c}$. It is evident that concave streamlines characterize the flow over the step. Chow [15] assumed that a curvilinear flow is accompanied by centrifugal forces normal to the flow direction. The pressure distribution deviates from the hydrostatic distribution and a non-linear form is assumed. This deviation, at any height, can be considered as $\gamma c$, where $c$ is defined as:

$$
c=\frac{v^{2} h}{g R}
$$

and the extra force imposed on the step is:

$$
F_{c}=\gamma s \frac{v_{2}^{2} h_{2}}{g R}
$$

where $R$ is the curvature radius. 
Now, we present an appropriate expression for $R$, whose determination depends on the streamline profile. Figure 4 shows the jump surface (convex curve) profile. The jump starts at the origin and ends at the point $\left(L_{j}, h_{2}\right)$. The concave curve indicates the closest streamline to the surface, and backward flow exists between the two curves. It seems rational to consider the curves as symmetrical, and that $y=\left(h_{2} / L_{j}\right) x$ is the line of symmetry. From the geometric point of view, the corresponding points in a symmetrical curve have the same curvature radius. The curvature radius of the point $\left(L_{j}, h_{2}\right)$, as the streamline's endpoint, equals the surface profile endpoint's curvature radius.

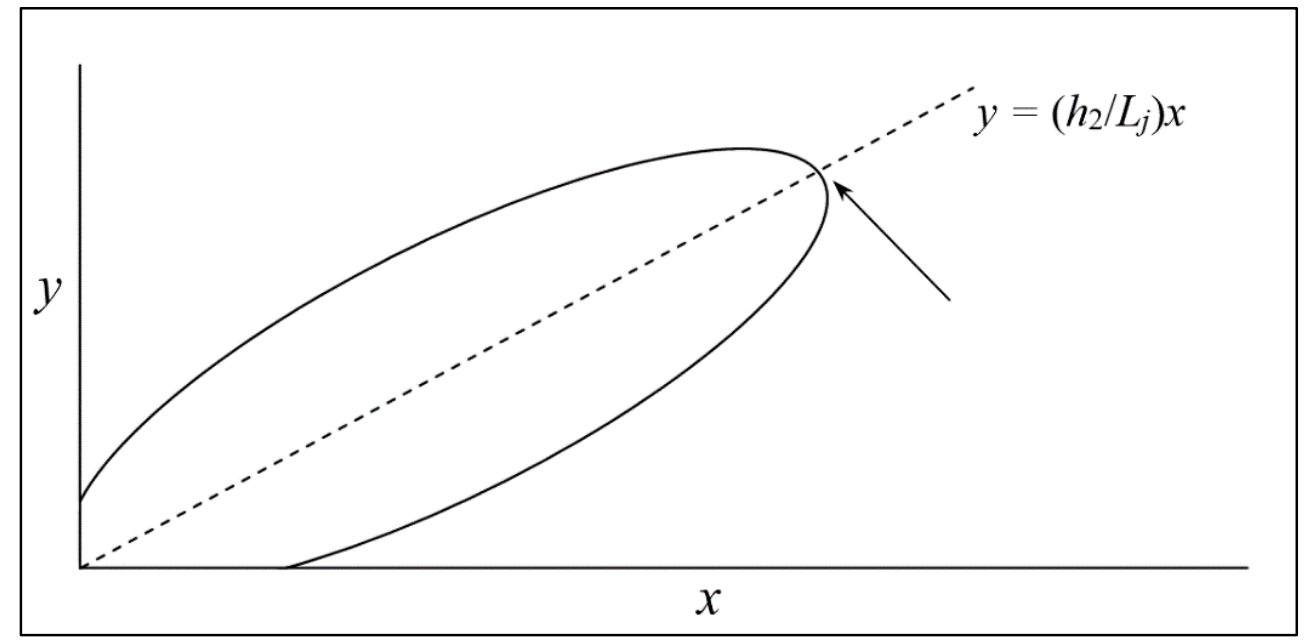

Figure 4. Jump surface profile symmetry and the upper streamline.

Hence, we could use a jump surface profile equation, and determine the curvature radius at the endpoint, and take that into account as the streamline's curvature radius at the same point. For this purpose, we could use the jump surface profile equation given by Gupta [16] as:

$$
1-\frac{y}{h_{2}-h_{1}}=\left(\frac{h_{2}-h_{1}}{L_{j}}\right)^{2}\left(\frac{L_{j}}{h_{2}-h_{1}}-\frac{x}{h_{2}-h_{1}}\right)^{2}
$$

in which $x$ and $y$ are the coordinates of the jump surface profile, and the origin is the channel bed at the jump's beginning. The curvature radius of any curve is defined as:

$$
\boldsymbol{R}=\left|\frac{\left(1+y^{\prime 2}\right)^{3 / 2}}{y^{\prime \prime}}\right|
$$

Computing the first and second-order derivatives of Equation (17) and substituting in Equation (18), $\boldsymbol{R}$ is obtained as:

$$
\boldsymbol{R}=\left|\frac{\left(1+\left[2\left(h_{2}-h_{1}\right)\left(L_{j}-x\right) / L_{j}^{2}\right]^{2}\right)^{3 / 2}}{-2\left(h_{2}-h_{1}\right) / L_{j}^{2}}\right|
$$

Replacing $x=L_{j}$ and $h_{2}=h_{3}+s$, the curvature radius at the step brink is gained as:

$$
\boldsymbol{R}=\frac{L_{j}^{2}}{2\left(h_{3}+s-h_{1}\right)}
$$


Using the continuity equation, and Equations (14) and (16), Equation (13) transforms to:

$$
\frac{h_{1}^{2}}{2}-\frac{h_{3}^{2}}{2}-\frac{s}{2}\left(2 h_{2}+\frac{v_{2}^{2}}{g}-s\right)-s \frac{v_{2}^{2} h_{2}}{g R}=\frac{q^{2}}{g}\left(\frac{1}{h_{3}}-\frac{1}{h_{1}}\right)
$$

In large Froude numbers, due to intensive jet flow against the step, Equation (21)'s accuracy diminishes. This could be justified by stagnation's great effect on the flow curvature. Thus, it seems necessary to include the Froude number's effect in the flow curvature term. To achieve this goal, we could assume a correction factor such as $C$, which is a function of $F_{1}$, and rewrite the momentum equation as:

$$
\frac{h_{1}^{2}}{2}-\frac{h_{3}^{2}}{2}-\frac{s}{2}\left(2 h_{2}+\frac{v_{2}^{2}}{g}-s\right)-C s \frac{v_{2}^{2} h_{2}}{g R}=\frac{q^{2}}{g}\left(\frac{1}{h_{3}}-\frac{1}{h_{1}}\right)
$$

Extracting $C$ from Equation (22), and using the experimental data of Forster and Skrinde [4], as shown in Figure 5, we could extract a power curve $\left(\boldsymbol{R}^{2}=0.36\right)$ as:

$$
C=7.17 F_{1}^{1.321}
$$

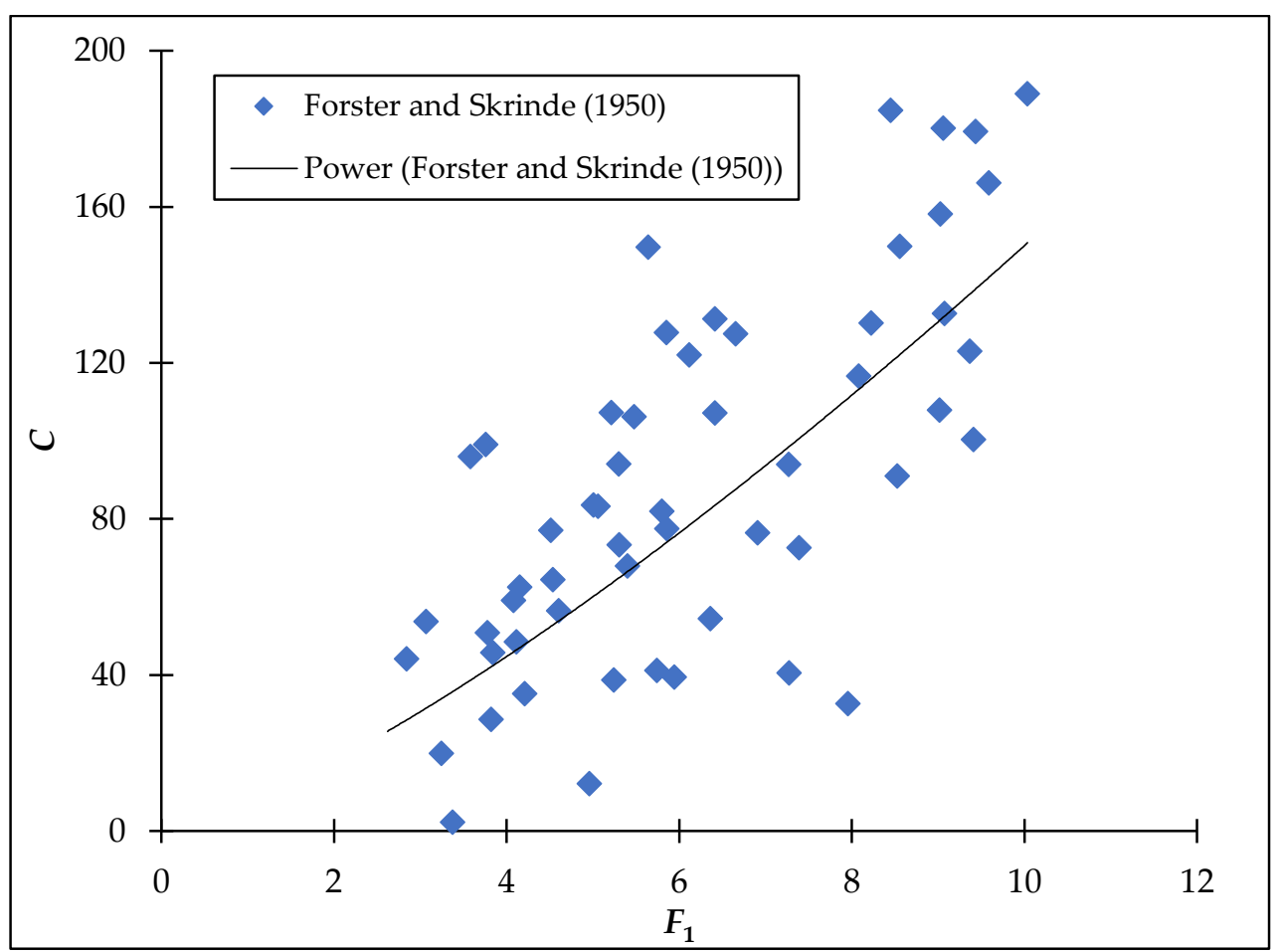

Figure 5. Curvature correction coefficient variation with initial Froude number.

Replacing $\boldsymbol{R}$ with Equation (20) and after a few manipulations:

$$
F_{1}^{2}=\frac{1-(Y+S)^{2}}{S(Y+S)^{-2}+4 C S Y^{-2}(Y+S-1)(Y+S)^{-1}\left(L_{j} / h_{3}\right)^{-2}+2\left(Y^{-1}-1\right)}
$$

where $F_{1}, Y$, and $S$ are the same as in Equation (2); $L_{j} / h_{3}$ is replaced by Equation (12); and $C$ is replaced by Equation (23).

Equation (24) constitutes the critical relationship between relative step height $S$, initial Froude number $F_{1}$, and conjugate flow depth $Y$. Figure 6 shows the variation of $Y$ with $F_{1}$ for different step heights. It should be noted that each curve's starting point is the least computable value of $Y$. In other words, $Y$ is not defined for lower initial Froude 
numbers. Additionally, Equation (24) indicates an approximate linear trend that rises with the slope of almost unity. Figure 6 also compares Equation (24)'s predictions with experiments of Forster and Skrinde [4] as well as the theoretical models of Hager and Sinniger [5], and Einwachter [3]. Equation (24) presents the most accurate curve with the closest consistency with experiments for different step heights as well as a fair range of initial Froude numbers. Even though previous theoretical models given by Hager and Sinniger [5] and Einwachter [3] diverge from experiments in large Froude numbers, Equation (24) fits the data well, even for high steps and large initial Froude numbers.

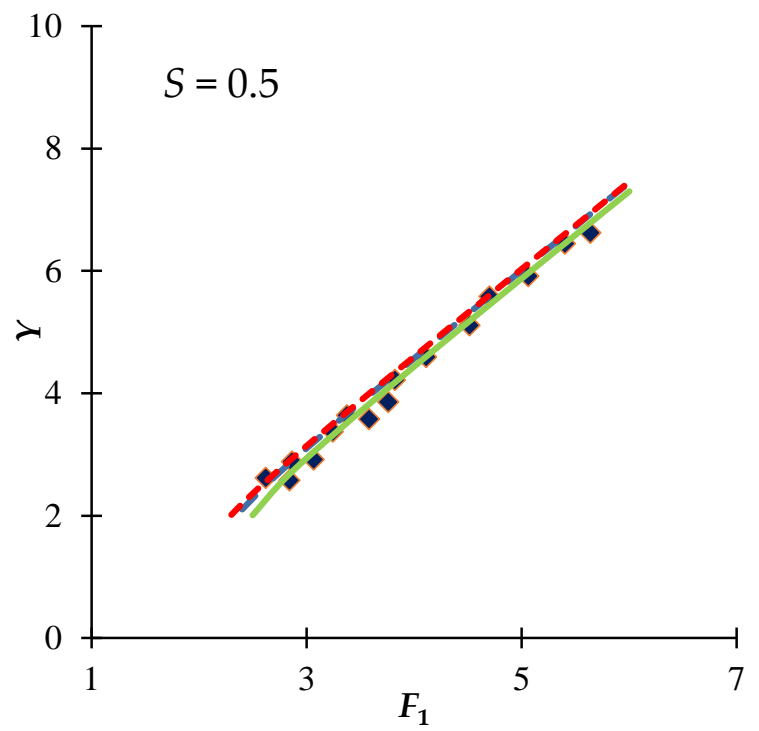

(a)

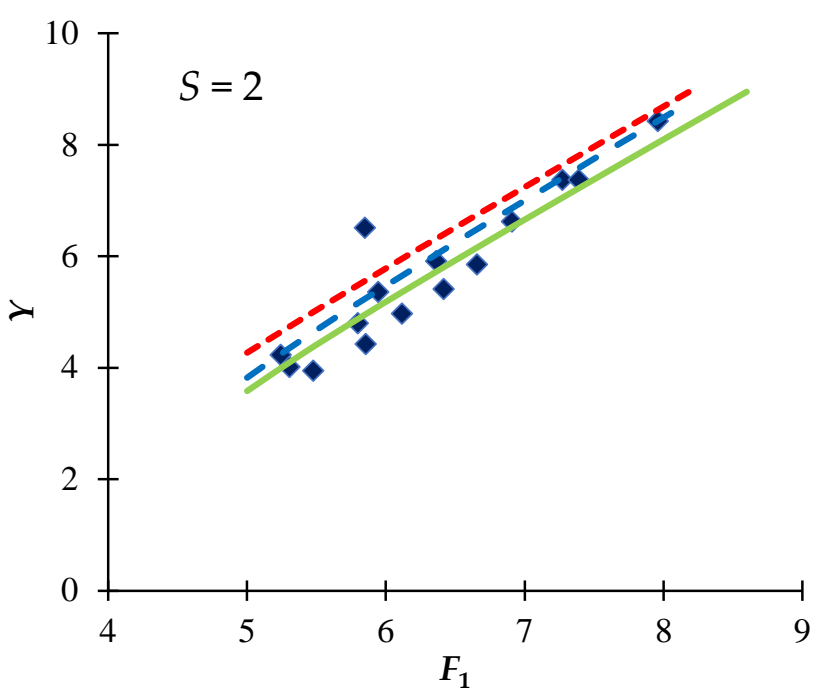

(c)

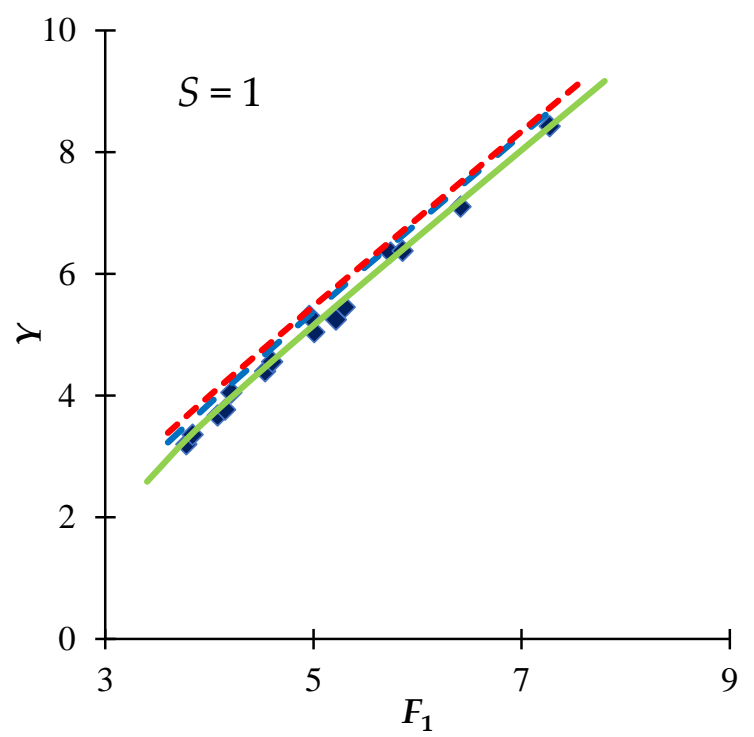

(b)

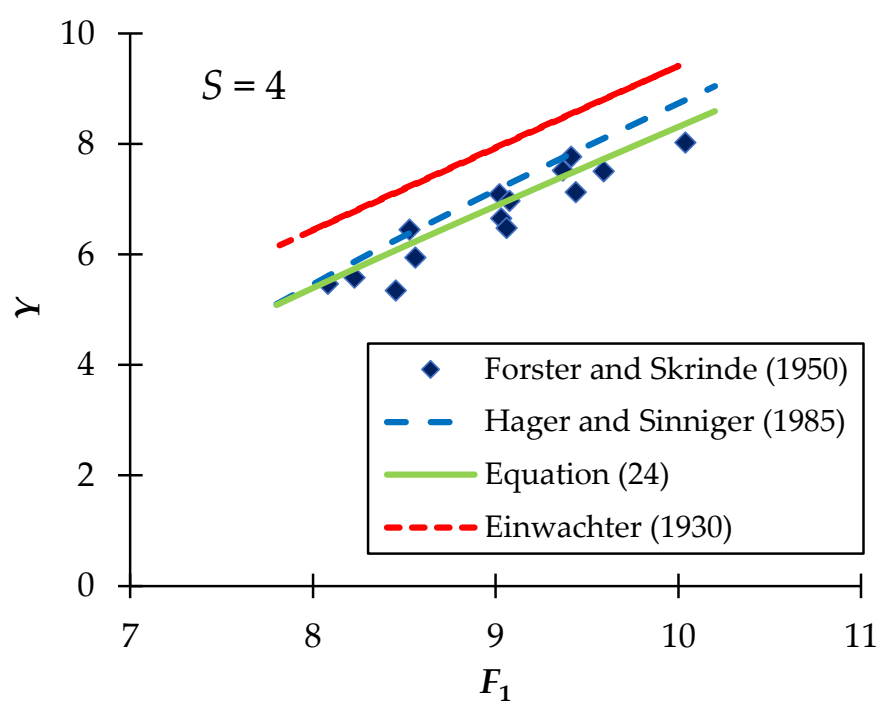

(d)

Figure 6. Conjugate flow depth variation with initial Froude number for different relative step heights: (a) $S=0.5$; (b) $S=1$; (c) $S=2$; (d) $S=4$. 


\subsection{Energy Dissipation}

Since energy dissipation has always been the intrinsic aspect of hydraulic jumps, here, we present an estimation of this parameter to detect the model's efficiency. For this purpose, using the specific energy equation, we obtain the relative energy dissipation as:

$$
\frac{\Delta E}{E_{1}}=1-\frac{Y+S+0.5 F_{1}^{2}\left\{(Y+S)^{-2}+Y^{-2}\right\}}{1+0.5 F_{1}^{2}}
$$

where $Y$ is replaced by Equation (24) to consider the small rise and the flow curvature effect. Figure 7 shows the relative energy dissipation variation with the initial Froude number. In Figure 7, we compare the experimental data from Forster and Skrinde [4] for different step heights, along with the data from Rajaratnam [10] for the jump without a step, and the theoretical estimation from Hager and Sinniger [5] with Equation (25).

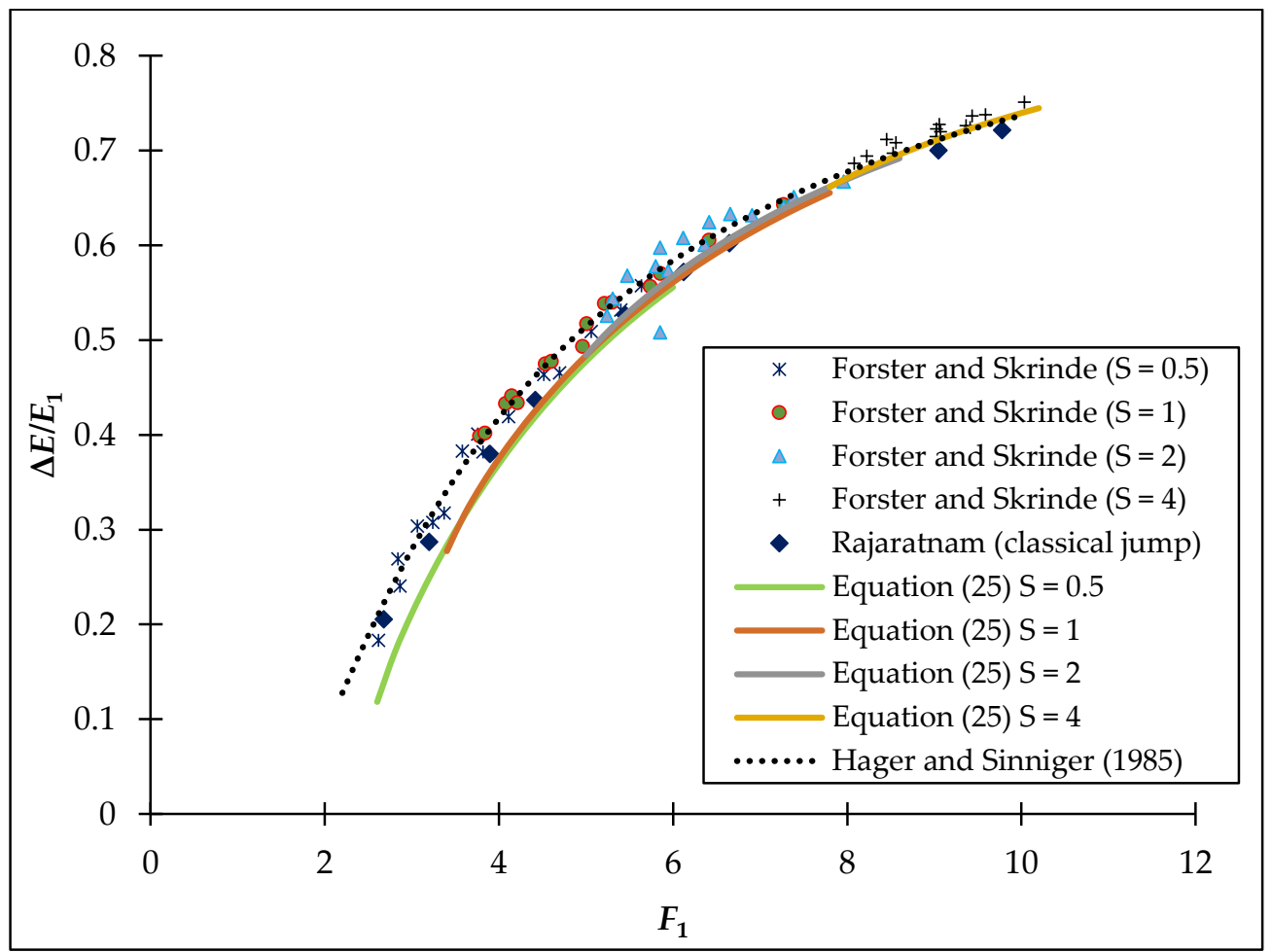

Figure 7. Relative energy dissipation variation with initial Froude number.

As indicated, the suggested curve pursues the data trend, which is energy dissipation increase with the initial Froude number. It was noted that the increased energy dissipation rate dwindled in larger Froude numbers. We also saw a minor divergence at lower Froude numbers between Equation (25) and the estimation of Hager and Sinniger [5]. Increasing the step height, and consequently the initial Froude number, resulted in an energy dissipation rise. Besides, the curves presented for different step heights in Equation (25) subsequently overlapped in significant initial Froude number ranges, meaning that in those ranges, step height does not make any difference in energy dissipation.

\section{Conclusions}

This paper presents a new theoretical model for the A-type hydraulic jump in a horizontal rectangular channel with a positive step. Based on an accurate closed-form approximation, and assuming a concave curvilinear flow profile at a positive step, we used a one-dimensional momentum equation and developed an expression for the conjugate flow depth, which agreed very well with previous measurements. Compared to previous 
theoretical models given by Hager and Sinniger [5] and Einwachter [3] that diverged from experiments with large Froude numbers, the proposed equation in this study fit the data well, even for high steps and large initial Froude numbers.

Moreover, based on the similarity between the hydraulic jump and turbulent wall jet, we presented a new method to estimate the jump length. The proposed equation showed a similar trend to the experimental data. However, for low Froude numbers $\left(F_{1}<5\right)$, the equation was less accurate in estimating the jump length.

We also estimated the jump's energy dissipation and proved the model's efficiency. However, it is noted that the increased energy dissipation rate dwindles in larger Froude numbers.

For future research, we recommend conducting more experimental studies on the hydraulic jump at a positive step to more accurately examine the subject as well as enhance the accuracy of the proposed equations.

Author Contributions: Conceptualization, M.M.; Methodology, M.M.; Data curation, M.M.; Writingoriginal draft preparation, M.M. and M.N.-S.; Writing-review and editing, M.N.-S.; Visualization, M.M.; Supervision, M.K. All authors have read and agreed to the published version of the manuscript.

Funding: This research received no external funding.

Data Availability Statement: Data sharing not applicable.

Conflicts of Interest: The authors declare no conflict of interest.

\section{References}

1. Hager, W.H. Energy Dissipators and Hydraulic Jump; Kluwer Academic Publishers: Dordrecht, The Netherlands, 1992.

2. Hager, W.H.; Bretz, N.V. Hydraulic jumps at positive and negative steps. J. Hydraul. Res. 1986, 24, 237-253. [CrossRef]

3. Einwachter, J. Wehre und Sohlenabstuerze (Weirs and Bed Erosion); Munich und Berlin, R. Oldenbourg: Karlsruhe, Germany, 1930.

4. Forster, J.W.; Skrinde, R.A. Control of the hydraulic jump by sills. Trans. Am. Soc. Civ. Eng. 1950, 115, 973-987. [CrossRef]

5. Hager, W.H.; Sinniger, R. Flow characteristics of the hydraulic jump in a stilling basin with an abrupt rise. J. Hydraul. Res. 1985, 23, 101-113. [CrossRef]

6. Quraishi, A.A.; Al-Brahim, A.M. Hydraulic jump in sloping channel with positive or negative step. J. Hydraul. Res. 1992, 30, 769-782. [CrossRef]

7. Husain, D.; Alhamid, A.A.; Negm, A.M. Length and depth of hydraulic jumps on sloping floors. J. Hydraul. Res. 1994, 32, 899-910. [CrossRef]

8. Negm, A.M. Hydraulic jumps at positive and negative steps on sloping floors. J. Hydraul. Res. 1996, 34, 409-420. [CrossRef]

9. Rajaratnam, N. Turbulent Jets; Elsevier: Amsterdam, The Netherlands, 1976.

10. Rajaratnam, N. The hydraulic jump as a wall jet. J. Hydraul. Div. 1965, 91, 107-132. [CrossRef]

11. Rouse, H.; Siao, T.T.; Nagaratnam, S. Turbulence Characteristics of the Hydraulic Jump. J. Hydraul. Div. 1958, 84, 1-30. [CrossRef]

12. Ohtso, I.; Koike, M.; Yasuda, Y.; Awazu, S.; Yamanaka, T. Free and Submerged Hydraulic Jumps in Rectangular Channels; Volume 35 of Report of the Research Institute of Science and Technology; Nihon University: Tokyo, Japan, 1990.

13. Chanson, H.; Brattberg, T. Experimental study of the air-water shear flow in a hydraulic jump. Int. J. Multiph. Flow 2000, 26, 583-607. [CrossRef]

14. Woycicki, K. Wassersprung, Deckwaize und Ausfluss Unter Einer Schiitze; Verlagder polnischen Akademie der technischen Wissenschaften, Warschau: Zurich, Switzerland, 1931.

15. Chow, V.T. Open Channel Hydraulics; McGraw Hill Book Company Inc.: Tokyo, Japan, 1959.

16. Gupta, N.K. A Dimensionless Study of the Longitudinal Element and Profile of Hydraulic Jump. Discussion 1966, 48, 1349-1356. 